\title{
TO OUR READERS
}

As announced in the last issue of 1970, this year's International Review of Social History was to be mainly devoted to the Paris Commune, a subject to be dealt with in two issues, combined into one for the occasion.

The preparatory work on this special issue has been conducted by an international committee of experts under the guidance of the Head of the French Department of the International Institute of Social History.

Although the necessary preparations were started well in advance, it has meanwhile turned out that the work involved far exceeds the anticipated time limit.

We regret that, under the circumstances, we have been obliged to revise our original publication scheme as follows.

Part 1 of Vol. XVI (1971) is herewith presented in the form of a standard issue, while a second issue is scheduled for publication in the near future.

Vol. XVII will be opened with the Commune issue of approximately 500 pages, and will be completed by another issue later in 1972 .

Frits de Jong Edz. 